\title{
Global Trends in Tax Administration
}

\author{
Michael D’Ascenzo AO
}

\begin{abstract}
This paper starts with the proposition that the descriptor, 'tax reform' can apply to different elements of a tax system. It argues that reforms affecting one aspect of the tax system often, but not always, provide the incentive or opportunity for reform of other components of the tax system. Within this broader context, sustainable tax reform requires good policy, an empowered, effective and efficient tax administration of high integrity, and community trust in the tax system. Trends in tax policy and the international tax environment impact on the strategies used by tax administrations to protect their revenue. At the same time, leading tax agencies seek to promote an investment climate by providing high levels of certainty and service to taxpayers. How well the tax agency is able to achieve these two, often disparate, objectives is of critical importance to the economy. This article outlines modern trends in tax administration that help leading tax administration reconcile these twin objectives.
\end{abstract}

\section{INTRODUCTION}

At its core a taxation system sustains the rights of citizens and investors, as well as funding the public and social infrastructure necessary for economic development and social equity. However, the tax system is made up of different components and these different threads are often intertwined and interdependent on each other. The scope of this paper is limited to the interaction between the tax law, including the laws governing administration, and tax agency reforms. Issues of policy or the wider context are merely touched upon. The focus of the paper is on global trends in tax administration; albeit that the wider cultural, political and social environment provides the backdrop as to what reform might be possible in any particular jurisdiction. The purpose of this paper is to outline trends in modern tax administration. At a time when governments want more with less from their tax authority, global trends in tax administration provide benchmarks for the modernisation of tax agencies.

\section{The interaction between key elements of the tax system}

When one speaks of reform in the tax arena such a reference could apply to different and often symbiotic elements of the tax system. For example, the reference could be to the laws that impose taxation, or to the laws that govern the administration of the tax system. The tag tax reform is sometimes also given to major changes to the tax administration, particularly the modernisation of the tax authorities of developing countries.

More often than not, major change to one aspect of the tax system is accompanied by changes in the other variables which together make up the system. For

\footnotetext{
${ }^{1}$ Michael D'Ascenzo AO is an Adjunct Professor at the University of New South Wales and a Professorial Fellow at the
} University of Melbourne. He was a former Commissioner of Taxation, 2006-2013, at the Australian Taxation Office. 
example, substantial reform of the tax law invariably necessitates changes to the tax administration. For example, in Australia the introduction of the Goods and Services Tax under the banner of 'Not a new tax - A new tax system' gave rise to substantial change at the Australian Tax Office (ATO) under the mantra 'A new tax office for a new tax system'.

In the context of countries seeking to modernise their tax system, necessary prerequisites to tax reform are appropriate rules governing how the tax law will be administered. These administration powers are important both from the perspective of providing certainty and procedural fairness to taxpayers, and for the purposes of ensuring that the tax agency has the necessary powers to carry out its tax collection responsibilities. For example, the People's Republic of China is reviewing its tax administration laws to promote a positive investment climate as a prelude to significant policy changes aimed at reforming its personal tax system. $^{2}$

Similarly breakthrough changes in tax agencies often need to be supported by legislative changes to the laws dealing with tax administration. So it was when the ATO moved to self-assessment that new administrative regimes were eventually introduced to make the operation of the tax system fairer and more certain for taxpayers. $^{3}$

While there is often interdependence between legislative change and improved tax administration, this is not always the case. For example, if legislative changes are introduced that are beyond the capacity of the tax agency to implement, the government's policy intent is likely to be frustrated. Leading tax administrations invest in information technology and seek to attract high quality recruits to provide them with the capability and agility required in modern economy.

Breakthrough improvements to tax administration can also be achieved without complementary legislative change. Often this requires the alignment of values and strategic directions, or the application of new thought paradigms regarding the relationship between the revenue authority and taxpayers. ${ }^{4}$ Vision and values are important to major cultural change or to the effectiveness and responsiveness of the tax authority. This is because good tax administration starts from the philosophy that underpins the thinking and actions of the tax agency. It's about the framework of the agency's corporate values; it's about its willingness to work with the community; it's about its ability to build trust in its administration by taking a fair and professional approach; it's about the agency's integrity; it's about being transparent; and it's about being empathetic as well as vigilant. Where these features coalesce, the agency's passion to enhance its performance becomes manifest.

\footnotetext{
2 The State Administration of Taxation(SAT) has begun a major tax administration modernization program for the period 2014-2020 guided by the goals set by the Third Plenary Session of the 18th Central Committee of the Communist Party of China held on November 12, 2013. To provide a firm foundation for modernizing tax administration, the SAT is seeking as a first step to review its core tax administration processes and revise the Tax Collection Law. As in other countries, this law sets out the common administrative provisions that apply to the main substantive tax laws (including the enterprise profits tax, the individual income tax, and the value-added tax).

${ }^{3}$ Joint Committee of Public Accounts, 'Report 326: An Assessment of Tax', AGPS, Canberra, 1993, at p.70-71.

${ }^{4}$ See for example new paradigms in the OECD's Forum on Tax Administration reports: 'Working Smarter: Executive Overview' (www.oecd.org/dataoecd/53/10/49428156.pdf); 'Corporate governance and tax risk management' (www.oecd.org/dataoecd/37/19/43239887.pdf); and 'Study into the Role of Tax Intermediaries' (www.oecd.org/dataoecd/28/34/39882938.pdf).
} 
Nevertheless, leaving aside the tax agency's own drive for reform, and disregarding the difficulties associated with the political aspects of wider tax reform, successful and sustainable reform of the tax system will usually require three key elements:

Firstly, good tax policy. ${ }^{5}$ From an administrative perspective, tax laws that lock in high levels of compliance are preferred, and many jurisdictions are buttressing their tax system with specific and/or general anti-avoidance provisions. ${ }^{6}$ Similarly, a tax law that is not administrable is not good policy. Accordingly it is desirable to have the voice of the administrator involved in the development and drafting of policy.

Secondly, the tax agency needs to be able to efficiently and effectively administer the tax system in a manner that builds taxpayer trust and confidence. Its ability to do this will impact on a taxpayer's propensity to comply and on the level of voluntary compliance with the tax system. As a general rule, this means that the tax agency needs to be sufficiently modern in its utilisation of technology so as to be able operate efficiently and effectively. It also means that the tax agency should exhibit high levels of integrity and provide taxpayers with service, certainty and procedural fairness. In this way the tax agency can help to enhance taxpayer trust and confidence in the tax system.

Thirdly, to be able to administer the tax system well, the tax agency needs to have the powers that facilitate efficient and effective administration, thus promoting high levels of voluntary compliance. For example, the tax agency needs adequate information gathering and debt collection powers, both for the purposes of deterrence and to underpin practical tax collection. Importantly, features of the tax system should provide taxpayers with certainty and the tax agency with legitimacy. Mechanisms that further this purpose include a robust integrity framework for the tax agency and the availability of taxpayer rights of objection and appeal. ${ }^{7}$ Moreover, the tax system should be supported by a wider infrastructure of checks and balances that protect taxpayer rights, including an independent judiciary and appropriate oversight of the tax agency. Underpinning tax administration with the rule of law, taxpayer rights to independent review and external scrutiny of the tax agency enhances the legitimacy of the tax agency and of the tax system.

\section{TAX POLICY}

The main aim of this paper is to outline global trends in tax administration. ${ }^{8}$ Nevertheless, a country's tax mix impacts on the strategies that a tax agency might use to promote high levels of compliance. For example, if there is heavy

\footnotetext{
${ }^{5}$ From a political perspective the policy will need to be supported by the electorate. What represents good tax policy is outside the scope of this paper, other than to note that good tax policy has to be able to be administered by the tax agency.

${ }^{6}$ See for example, the United Kingdom's general anti-avoidance rule, and Brazil and Chile's new controlled foreign corporation laws.

${ }^{7}$ See OECD Forum on Tax Administration (FTA), 'Taxpayers' Rights \& Obligations' (www.oecd.org/dataoecd/24/52/17851176.pd).

${ }^{8}$ See also, Chris Evans, 'The fiscal outlook for South Africa: challenges and opportunities', South African Institute of Tax Professionals, Tax Indaba 2014.
} 
reliance on personal income tax, the compliance risks for individuals are likely to be different from those in relation to multinational enterprises. The tax administration practices are also likely to be different and tailored to particular market segments and to tax system risks identified in each market or taxpayer type. Accordingly, the tax mix will be influential on the risk management approach adopted by the tax agency and the consequential resource allocations that follow.

In these circumstances one cannot generalise on tax administration without noting the global trend away from company tax and the increased reliance on consumption taxes. These trends were observed back in 2004 by Warren in relation to the experiences of OECD member countries. ${ }^{9}$ They have tended to become more prominent in recent times.

\section{Firstly taxes such as company taxes have declined}

Many commentators would argue that the mobility of capital makes the corporate tax base fragile. ${ }^{10}$ This is exacerbated under the current global architecture for international taxation. Hence the current focus on the OECD's Base Erosion and Profit Shifting (BEPS). ${ }^{11}$ The current OECD and G20 focus on BEPS highlights the problem of double non-taxation and the impact of tax competition on the size of the corporate tax base. There is growing concern that the current international tax framework, based as it is on the concepts of source and residency, is not fit for purpose in an increasingly global and e-commercial world.

The BEPS action plan has, amongst other things, recommended the use of general anti-avoidance and anti-profit shifting provisions and controlled foreign corporation provisions to support the corporate tax base. How well these provisions operate from the perspective of taxpayers, especially large business, and from the perspective of the revenue will be relevant to both the relationship that exists between these groups, and their effectiveness in protecting the existing corporate tax base. The judiciary will also be pivotal as to the effectiveness of these provisions over time.

On the other hand, policy making in most countries recognises the importance of large businesses and multinational enterprises to the economy. Accordingly, tax agencies should only seek to recover the tax that is payable in accordance with the legislative policy as reflected in the tax law. It is not the tax agency's role to claw back revenue which the legislature, either by statute or treaty, has excluded from a country's tax net.

The broader measure of tax agency performance is its ability to secure high levels of compliance in accordance with the law, while fostering an environment conducive to investment. The tax agency's ability to do this will be of critical importance to a country's finances. In terms of effectiveness there is no substitute for a professional tax administration of high integrity that follows the rule of law.

\footnotetext{
${ }^{9}$ Neil Warren, 'Tax: Facts, Fiction and Reform', Australian Tax Research Foundation, Research Study No. $41,2004$.

${ }^{10}$ Report to the Treasurer, "Australia's Future Tax System” (December 2009), Commonwealth of Australia, 2010.

${ }^{11}$ OECD (2013), Action Plan on Base Erosion and Profit Shifting, OECD Publishing.

http://dx.doi.org/10.1787/9789264202719-en.
} 
In this way the agency provides consistency and certainty to taxpayers. On the other hand, the tax agency needs to be vigilant to abuses of its tax system. Global experience shows that the corporate tax base is likely to diminish if the antiavoidance and anti-profit shifting provisions are not effective for whatever reason. $^{12}$

With the trend for reduced company taxes (and lower corporate revenue), the residual question that arises is what should take its place? While a 'growing the revenue pie' philosophy might succeed in securing needed revenue, that is not always the case, particularly as competitor countries retaliate with their own reductions in the company tax rate. Moreover there is usually a significant lag between tax rate reductions and substantial improvements in economic activity.

Often countries faced with this dilemma resort to indirect taxes to meet budget requirements. For example, in most European countries, indirect taxes now represent a large proportion of the total tax take, and corporate taxes usually represent only a small percentage of the tax mix.

\section{The trend away from global income tax and an increased role for consumption taxes}

Related observations made by Warren (2004) were a trend away from global income taxes to different source of income taxed at different rates, as well as increased reliance on indirect taxes, particularly consumption taxes. A shift away from global income tax represents policy settings by the government, including increasing or decreasing the burden of taxation on particular segments or activities. The policy settings in effect pick winners and losers, based on economic or social assumptions and objectives, and arguably have a distortive effect. Scheduler approaches also raise their own complexities such as the allocation of income to a particular schedule item.

The reduced reliance on company taxation, the shift to scheduler approaches, and the increased role of consumption taxes have implications for a country's tax mix. ${ }^{13}$ For example, most OECD countries now have an increased role for consumption taxes in funding government expenditure. ${ }^{14}$ While technological changes have reduced the compliance costs of Value Added Tax (VAT) systems, they remain regressive in nature. They are often tied to some sort of compensation package to assist people on lower incomes. In addition some VAT systems have carve-outs for items such as food and education. In developing countries many low income groups are excluded from the tax net by high thresholds, given the difficulties of administration, compliance cost issues and social policy.

\section{REVENUE REQUIREMENTS}

\footnotetext{
${ }^{12}$ See for example, The House of Commons Committee of Public Accounts, Management of Large Business Corporation Tax, Thirtieth Report of Sessions 2007-08 page 11. See also Q83 and Q84 in the Oral Evidence before the House of Commons Committee of Public Accounts, 28 January 2008, in relation to transfer pricing.

${ }^{13}$ Australia's tax mix has shifted in recent times towards personal income tax, mainly as a result of bracket creep: Martin Parkinson, 'Fiscal Sustainability \& Living Standards - The Decade Ahead', This Sydney Institute, 2 April 2014. Cf. Mathew Lester, 'Simple demonstrations of the tax mix dilemma facing RSA', South African Institute of Tax Professionals, Tax Indaba 2014.

${ }^{14}$ John Preston, 'Shaping the Tax System', PWC Tax administration: Global Trends, 2012.
} 
The high demand for the whole range of public goods and services shows no sign of abatement in most countries. Developing countries have to invest in new infrastructure to promote a positive investment climate and to attract much needed foreign investment. Developed economies generally face increasing expectations from their citizens in the level and quality of services provided by government. For some countries these issues are exacerbated by high levels of public debt and/or an aging population. Most countries are looking to find sustainable sources of revenue to fund their public policies. Given this demand for revenue, the trends identified by Warren (2004) have intensified in recent times, and particularly in the aftermath of the global financial crisis.

Governments around the world have been under significant pressure to address the need for increased tax revenues, a situation likely to continue long term, with tax authorities continuing to step up efforts to improve global cooperation, reduce tax avoidance and evasion, and improve the efficiency and effectiveness of their approaches to tax audit controversies. ${ }^{15}$

\section{OECD forum on tax administration}

Over the last decade the OECD's Forum on Tax Administration (FTA) has shone the spotlight on tax administration issues. Within the context of a global economy, rapid technological change and fiscal challenges for government, the forum aims to improve taxpayer services and tax compliance - by helping revenue bodies increase the efficiency, effectiveness and fairness of tax administration and reduce the costs of compliance. It seeks to do this by sharing experiences of revenue bodies, promoting co-operation between member countries, and developing joint programmes of action on key tax administration issues. For example, at the Ninth Meeting of the FTA (Dublin 23-24 October 2014) participants agreed:

- A strategy for systematic and enhanced co-operation between tax administrations;

- To invest the resources needed to implement the new standard on automatic exchange of information; and

- To improve the practical operation of the mutual agreement process.

The work of the FTA is helping tax agencies to improve their administrations. For example, given the challenging cost reduction targets set for many tax agencies, and the expectation that they also maintain or even improve their standards of service delivery and the effectiveness of their of their activities, the search for best practice is being facilitated by the FTA. The FTA is undertaking a project, 'Working Smarter' to examine measures taken by revenue bodies to reduce costs and increase efficiency in the areas of structuring, compliance, service delivery, and legislation. ${ }^{16}$ More generally, the FTA has provided thought leadership on modern tax administration. ${ }^{17}$

\footnotetext{
${ }^{15}$ KPMG's 2009 Tax Department Survey, Good, Better, Best: The race to set global standards in tax management.

${ }^{16}$ FTA, 'Working Smarter: Executive Overview' (www.oecd.org/dataoecd/53/10/49428156.pdf).

${ }^{17}$ See for example, FTA's 'Co-operative Compliance: A Framework from Enhanced Relationship to Co-operative

Compliance' (http://www.oecd.org/tax/administration/co-operative-compliance.htm); 'Right from the Start: Influencing the Compliance Environment for Small and Medium Enterprises' (www.oecd.org/dataoecd/41/14/49428016.pdf); 'Corporate governance and tax risk management' (www.oecd.org/dataoecd/37/19/43239887.pdf); 'Study into the Role of Tax Intermediaries' (www.oecd.org/dataoecd/28/34/39882938.pdf); and 'Standard Business Reporting' (www.oecd.org/dataoecd/36/52/43384923.pdf).
} 


\section{Global Trends in TAX AdMinistration}

\section{Tax agency legitimacy}

As Evans (2014) ${ }^{18}$ observes there has been a trend to give the tax agency greater legitimacy, and also to quicken their pace of change. In some countries these objectives underpin moves to make tax agencies autonomous or semiautonomous structures that provide independence of tax administration from the political sphere. There is in these situations an assumption that a change in status would provide the tax agency with more flexibility and speed of response in terms of pay outcomes, recruitment and other administrative processes, and importantly, independence in decision making. Whether this assumption holds true will depend on the realities of the particular jurisdiction.

With greater autonomy comes greater responsibility, and accordingly any change in the status of the tax authority is usually accompanied by a suite of additional checks and balances. This trend towards tax agency independence is often accompanied by taxpayer appeal rights, external scrutiny of the tax agency, for example, the government audit office and a tax ombudsman, as well as parliamentary reviews.

Leading tax agencies often have at the centre of their reform initiatives improvements in the skill level of their officers. This has been sought to be achieved through flexible recruitment practices designed to induct quality applicants, a focus on training and development, and the development of systems that capture and allow the repetition of best practice. The modern trend for tax agencies is for more highly skilled officers, with merit-based promotion, and performance management and development systems.

\section{Self-assessment}

For any country with a sizable tax population, self-assessment is a more efficient system for administering the income tax system. Full assessment models tried to scrutinise all tax returns to determine the tax owing by the taxpayer or the refund due to the taxpayer. This approach is resource intensive and, to do properly, usually requires more resources than are available to the tax agency. The nature and criticality of this activity results in a time lag for the issue of refunds, and limits the resources available for other compliance activities.

Under self-assessment, tax returns (if they need to be lodged) are accepted on their face with follow up action taken subsequently if required. The exception is in relation to high risk returns, particularly VAT refund requests, where risk filters require prior review of the more risky claims.

\footnotetext{
${ }^{18}$ Chris Evans, 'The fiscal outlook for South Africa: challenges and opportunities', South African Institute of Tax Professionals, Tax Indaba 2014.
} 
One criticism of self-assessment is that it shifts compliance costs onto the taxpayer or their agent. In order to soften this impact, the move to selfassessment is often accompanied by legislative change to make the system fairer and more certain for taxpayers (that is, changes often have to be made to the interest and penalty regimes of the existing system to compensate for the shift of responsibilities to taxpayers and their agents).

In addition there is an implicit expectation that the tax agency will assist and provide services to taxpayers and their agents to help them carry out their tax responsibilities. In a self-assessment tax system the risk is that taxpayers may be intentionally or accidently apply the law incorrectly. When taxpayers do not fully understand the law that applies to them, they run the risk of being in error. Modern tax agencies have a range of specialised approaches for each of their taxpayer markets to assist them in getting it right, from personal tax payers right through to their large companies and high net wealth individuals. In many countries, particularly those which operate VAT systems, small business is a particular segment of focus given the importance of this sector to the effective operation of these regimes.

As well as the provision of services, such as guides, websites, call centres, ruling systems and the like, self-assessment also requires new thinking in relation to the tax agency's compliance strategies. When taxpayers choose not to apply the law correctly, they obtain an unfair advantage over honest taxpayers and run the risk of later detection by the tax administrator. The administrator seeks to facilitate a level playing field but works in an environment of information asymmetry - it isn't immediately obvious who may not have complied or the underlying reasons why they have not done so. The administrator can, to an extent, control risk exposure of the broader community by building systems, such as risk engines to detect potential errors, and by conducting expensive risk assessments and audits to detect and correct positions which do not accord with the law. These actions are typically after the fact, although they do have a deterrent effect.

Many countries now use compliance models which differentiate between the economic, psychological, and social circumstances of taxpayers. This responsive regulation approach is based on the proposition that effective enforcement requires a dynamic and gradual application of less to more severe sanctions and regulatory interventions. In more recent times countries have placed increasing emphasis on 'Right from the Start' and 'Prevention is better than cure' strategies. The modern trend is to regard service and enforcement as part and parcel of a more holistic approach for improving levels of compliance.

\section{Review of the administration act}

The tax administration provisions, whether situated in a separate Tax Administration Act or in the substantive tax laws, should support effective and efficient tax administration. ${ }^{19}$ However it is critically important that they strike the right balance between administrative efficiency and taxpayer rights. For example, the introduction of self-assessment in Australia necessitated wholesale changes to

\footnotetext{
${ }^{19}$ See for example, Australia's Taxation Administration Act 1953, including Schedule 1 to that Act.
} 
the penalty and interest provisions and the introduction of binding public ruling and reviewable and binding private ruling systems. ${ }^{20}$

An on-going focus on tax administration provisions is appropriate because they calibrate the scales in terms of the relationship of the tax authority with the community. The style and effectiveness of tax administration is often governed by what these provisions allow or do not allow. Just as important however, is the culture of the tax administration and the integrity of its officers.

\section{Modernisation of tax administrations including the use of technology and analytics}

Given the call to do more with less, modern tax administrations are making greater use of technology and analytics to improve both their efficiency and their effectiveness. For example, data matching has become an increasingly effective tool for tax agencies - providing a powerful deterrent strategy; helping to detect non-disclosure of income; and facilitating the pre-filling of returns.

Increasingly the role of any modern revenue authority, indeed any business, is about making sense of data that is now available more readily and more completely. For tax administrators worldwide, this world of near infinite data and emphasis on management of intelligence has arrived. A key role of tax administrations in this environment is to manage information in a way that allows differentiated approaches in providing assistance to people and in protecting people from those that default on their legal and civic duties. The effective use of digital information and the employment of analytics - including data and text mining and visualisation tools - are at the centre of modern tax administration. Optimising the potential of data can also help spur innovative thinking and new approaches.

Beyond maintaining the integrity of the tax system, there is a growing community expectation of excellent service. Leading tax agencies are looking at ways to reduce compliance costs for taxpayers by keeping taxpayers out of the system (for example using withholding arrangements) or at ways to make their tax responsibilities easier, cheaper and more personalised for them such as the prefilling of tax returns.

In the Web 2.0 world, those community expectations will only grow. People expect technology to provide them with more than passive viewing of static pages of information. They expect to be increasingly able to interact online seamlessly with tax agencies and with government more generally, and to interact in nontraditional and non-bureaucratic ways. In such a world there is a premium for tax agencies to have a close working relationship with software developers. Given the touch of most tax agencies, it is desirable that they be influential in the development of the government's digital strategy - promoting taxpayer-friendly digital processes and standards that help make the country more efficient. It is increasingly argued in academic literature that the proliferation of internet connected devices and digital communications should be viewed as the initial phase of a fundamental shift in global social interaction, personal participation

\footnotetext{
${ }^{20}$ Taxation Laws Amendment (Self Assessment) Act 1992.
} 
and corporate productivity, with implications akin to the introduction of the printing press and the Industrial Revolution. Modern tax administrations need to be responsive to this changed environment, and indeed should seek to be at the forefront of some of these developments.

\section{Market segmentation, risk management and differentiation}

Increasingly, leading tax agencies are building closer relationships with their communities. Structurally this trend often starts with them organising themselves around different groups of taxpayers, commonly referred to as "market segments", such as large businesses, medium businesses, small and micro businesses, and high wealth individuals.

The rationale for a differentiated approach is that the various market segments have different needs in relation service, assistance and guidance, and they present different types of tax risks. The breakthrough here is to conceptualise compliance management in terms of all the levers that could help address the causes of a particular compliance risk or taxpayer need. This means that if, for example, the cause of non-compliance involved misunderstandings as to what was required, then service, assistance, technical guidance and public rulings could be the best cures. Similarly if the processes associated with fulfilling one's responsibilities made compliance difficult then the best strategy might be to make the processes easier. Naturally, in order to protect honest taxpayers, harder edged strategies such as reviews, audits and prosecution action are also necessary to foster high levels of voluntary compliance - the stick and the carrot are integral parts of a coherent and targeted compliance programme.

The guiding principle to keep in mind is that the tax agency's strategy for administering the tax system should determine its organisational structure and not the other way around. What leading tax administration are now doing is to harness the power of analytics to better understand taxpayer needs and risks to the revenue. ${ }^{21}$ Analytics is used to predict and analyse areas of risk and emerging patterns in behaviour. It is fast becoming central to supporting and protecting taxpayers, tailoring service delivery and operating an efficient tax administration. Leading tax agencies are structuring themselves based on this better understanding of taxpayer need and risks to the tax system. They are then devoting their scarce resources to meeting taxpayer needs and to addressing the highest risks. This approach not only optimises the return on resource usage by the tax agency but also reduces compliance costs of honest taxpayers.

\section{Enhanced risk management systems}

Like any government agency, a tax authority's resources are limited. In order to optimise levels of compliance many leading tax agencies operate on a riskmanagement basis. This means that they make informed choices as to how they allocate their scarce resources to best serve the community. This involves anticipating potential risks (help and assistance activities, information and guidance, and prevention is better than cure strategies), as well as detecting and

${ }^{21}$ Australian Commissioner of Taxation, 'The effective use of analytics in public administration: The ATO Experience', Australian Institute of Company Directors, June 2012. 
dealing with existing risks (again by addressing the causes of the risk as well as the symptoms).

Risk management simply means the development of a systematic approach for identifying and prioritizing the largest risks to the tax system, and developing comprehensive strategies for managing these risks. Behind this simple concept, leading tax agencies have made significant investments in enhancing their analytical systems, core tax administration processes, and information systems to better support risk management. In doing so, effective tax agencies commonly manage their risks through three different 'lenses' or perspectives.

1. The Tax lens: This involves identifying the biggest risks for each major tax, regardless of the taxpayer segment and industry, and developing comprehensive compliance strategies for controlling these risks. The compliance strategy might entail a balanced set of treatments for addressing the tax risk. This could involve the issuance of technical guidance or regulations, customised taxpayer service products, or a specialised enforcement approach, for example developing risk filters to identify the presence of the risk in specific tax returns.

2. Market segment and Industry lenses: Having identified the main risks for each major tax, tax agencies would then assess within each tax the risks that are specific to each segment (e.g., large, medium, and small enterprises, and individuals) and within each segment strategic industries. For the large enterprise segment, it is common for the tax agency to create permanent industry teams for the country's major industries; for small enterprises - which typically operate in many industries - benchmarks could be developed outlining the financial ratios that might be expected from selected industries. National plans would be developed to address the risks that have been identified and relevant strategies would be based on an appropriate mix of service and enforcement applicable to the high priority risks.

3. The Taxpayer lens: Leading tax agencies determine higher risk taxpayer at the entity level. In doing so, each taxpayer might be assigned to a particular risk group based on their risk level and a set of treatments proportionate to the risk will be developed for each group (for example, strategies comprising both services and audit activities). At the entity level, under a risk management approach, the higher risk taxpayers would tend to receive a greater audit focus while lower risk taxpayers would receive more of a service focus. Some tax agencies have set up separate areas for dealing with large companies and high net wealth individuals. The entity in these situations for say companies includes the company's subsidiaries and affiliates. For high net worth individuals, the analysis includes other entities controlled by the individual.

Best practice tax risk management practices focus on preventing and resolving tax risk issues as efficiently and effectively as possible. This requires the risk treatment plan to consider the appropriate mix of activities that prevent a tax risk as well as resolving the risk once it arises. 


\section{Greater focus and cooperation on international tax avoidance}

A global trend that has been evident, particularly since the global financial crisis, has been the attention given by tax agencies to cross-border tax avoidance issues, in part to secure additional taxes to make up for falling revenues associated with the economic slowdown. Associated with rising community expectations, there is also a need to secure funding for improvements in public sector services and infrastructure.

The global economic downturn led to an overt international focus on good corporate governance and tax risk management by banks and multinational enterprises. This was underpinned by increasing public and government scrutiny of the tax system and of the role and responsibilities of large business. Within this climate, tax administrations have responded with a united call for increased disclosure and transparency, while encouraging and promoting robust tax governance processes within company risk management frameworks. This increased attention on international avoidance has taken place at three levels:

1. Within tax agencies, countries are developing comprehensive strategies for dealing with international tax compliance risks. These strategies have included requiring taxpayers to make greater disclosures on their tax returns of their international dealings and foreign bank accounts.

2. Across countries, tax agencies have improved cooperation, have agreed to new international exchange of information protocols, and some have moved to coordinated approaches with other tax agencies, including the conduct of joint audits.

3. At a global level, the OECD and G20 countries have focused on base erosion and profit shifting issues and country-by-country reporting.

For some time now the OECD FTA has recognised the importance of improving tax compliance through cooperation. There is now unprecedented co-operation amongst many of the FTA members, including significant sharing on information on offshore arrangements using tax secrecy jurisdiction. More recently many countries have signed up to the OECD's exchange of information protocols which should see a step improvement of information flows between tax agencies.

\section{Making it easier, cheaper and more personalised for taxpayers}

Leading tax agencies describe in detail the rights of taxpayers as well as their responsibilities. In Australia this approach is supported by a Taxpayers' Charter. If the Taxpayers' Carter is given relevance in the tax agency then it helps to shape culture in a way that helps to bridge the gap between the tax agency and taxpayers and their advisers. ${ }^{22}$

${ }^{22}$ Simon James, Kristina Murphy and Monika Reinhart, 'Taxpayer' Charter: A Case Study in Tax Administration',7 Journal of Australian Taxation, 336 (2004). 
The quality of service that tax agencies provide to their taxpayers is dependent on the values of the organization. In essence the staff of the tax agency must believe in treating taxpayers in the way that they would expect to be treated if an ideal relationship is to be established between the tax authority and citizens. It is the values of the tax authority that allow it to be empathetic to the needs of taxpayers.

As part of a culture of providing assistance to taxpayers, tax agencies are expanding their electronic service offerings. These include expanding the take up rates for electronic-filing and electronic payment as well as providing electronic portals that allow taxpayers and their advisors to self-manage various aspects of their tax affairs on-line such as such as registering on-line, checking their account balance online, requesting refunds, accessing previous tax returns, submitting enquiries by email and accessing responses to their queries online.

The website of leading tax agencies provide easy to follow step by step guidance for taxpayers, particularly for individuals and small businesses. These websites also include decision trees, calculators and self-help tool to make compliance easier. These tools are complemented by a telephone help service and a 'no strings attached' purely assistance visits for small businesses.

In developing these tools and other products leading tax administrations apply user-based design principles to ensure that they are designed from the perspective of the taxpayer. User-based design helps to ensure that the activities of the tax agency are user-friendly and apt to minimize compliance costs for taxpayers. In some counties the legislature seeks to minimize the tax compliance burden on personal income tax payers through the use of withholding arrangements, including final withholding at source. In other countries the tax agency uses third party information to pre-fill the return forms of individual taxpayers to make tax compliance easier and cheaper for them. ${ }^{23}$ Pre-filling is dependent on the electronic lodgement of returns and electronically acquired third party data. Tax administrations working on-line and promoting digital approaches to both service and compliance is itself a global trend.

\section{A focus on registered tax agents}

Taxpayers' agents and advisers are a key group for influencing the behaviour of their clients. Proving them with easy to us electronic interfaces with the tax agency such as the ATO's Tax Agent Portal, and providing them with advice and technical and procedural guidance are ways to assist them and to streamline and promote the proper compliance of their clients. In other words, by assisting the tax agents the tax authority can leverage that assistance across all the tax agents' clients. $^{24}$

The tax profession needs to be capable, professional and of high integrity is if is to positively influence their client in terms of proper compliance behaviour in

\footnotetext{
${ }^{23}$ Pre-filling is designed to make the process of preparing tax returns easier, quicker and more accurate for both tax agents and self-preparers which means there is less chance of surprises down the track. See OECD FTA, 'Using Third Party Information Reports to Assist Taxpayers Meet their Return Filing Obligations: Country Experiences With the Use of Prepopulated Personal Tax Returns' (www.oecd.org/dataoecd/42/14/36280368.pdf).

${ }^{24}$ Commissioner of Taxation, 'Tax Practitioner Action Plan', CPA Sydney Professional Accountant's Group, 2012: http://www.ato.gov.au/content/00307038.htm.
} 
accordance with the law. While perhaps not yet a global trend, the regulation of the tax profession is likely to be a future global agenda. For example, Australia has recently revised its regulatory rules for promoting a capable tax profession of high integrity. ${ }^{25}$

\section{Developing an enhanced relationship, particularly with large business}

There has been a discernible shift away from command and control to risk management approaches designed to foster voluntary compliance. This trend includes the use of prevention rather than cure strategies aimed at the causes of non-compliance, and the use of compliance models that differentiate the different postures of taxpayer to compliance. The trend is towards responsive regulation. ${ }^{26}$ Consistent with this trend, an increasing number of tax administrations are seeking to enhance their relationship with large business:

"An adversarial relationship between tax administrations and multinational corporate taxpayers serves neither of our purposes well and is contrary to our common goals, which are earlier and greater certainty, consistency, and efficiency. To this end, we agreed that we need to create innovative strategies for issue resolution that are less time and resource intensive for both, while still promoting a climate that encourages compliance with tax laws." 27

\section{Co-operative compliance}

Mutual transparency is being increasingly recognised globally as a means to mitigate tax risk. Australia for example has for some time coined the term 'cooperative compliance' and the Netherlands has pioneered 'horizontal monitoring'. The premise of these approaches is dependent on a professional tax administration that demonstrates the attributes of commercial awareness; impartiality; proportionality; openness; and effective risk-management. This level of professionalism and integrity should encourage taxpayers, and large corporate taxpayers in particular, to engage in a positive relationship with the revenue agency.

\section{Tax in the boardroom}

To make tangible the benefits of an enhanced relationship some tax agencies has sought to bring material tax risks to the attention of company boards. ${ }^{28}$ Recently the OECD updated its 'Guidelines for Multilateral Enterprises'. These Guidelines are recommendations by governments to multinational enterprises to promote responsible business conduct in a global context. They include a Tax Chapter that reads as follows:

\footnotetext{
${ }^{25}$ Tax Agent Service Act 2009.

${ }^{26}$ Anuhka Bakker and Sandor Kloosterhof, 'Tax Risk Management: From Risk to Opportunity', IBFD ed., 2009. See also Sagit Leviner, 'A New Era of Tax Enforcement: From 'Big Stick' to Responsive Regulation', Michigan Law School, 2006; and Valerie Braithwaite, 'Responsive Regulation and Taxation', Law \& Policy, Vol. 29, No 1, January 2007.

${ }^{27}$ See 'Study into the Role of Tax Intermediaries', OECD Forum on Tax Administration, 2008.

${ }^{28}$ See 'Tax Risk Management', 2007, Lexis Nexis/Butterworths; Ernst and Young, 'Tax risk: External change, Internal Challenge-the Australian perspective: Global Tax Risk Survey 2006-2007', 2007; and OECD (2011), 'OECD Guidelines for Multinational Enterprises', OECD Publishing: http://dx.doi.org/10.1787/9789264115415-en.
} 
"1. It is important that enterprises contribute to the public finances of host countries by making timely payment of their tax liabilities. In particular, enterprises should comply with both the letter and spirit of the tax laws and regulations of the countries in which they operate. Complying with the spirit of the law means discerning and following the intention of the legislature. It does not require an enterprise to make payment in excess of the amount legally required pursuant to such an interpretation. Tax compliance includes such measures as providing to the relevant authorities timely information that is relevant or required by law for purposes of the correct determination of taxes to be assessed in connection with their operations and conforming transfer pricing practices to the arm's length principle.

2. Enterprises should treat tax governance and tax compliance as important elements of their oversight and broader risk management systems. In particular, corporate boards should adopt tax risk management strategies to ensure that the financial, regulatory and reputational risks associated with taxation are fully identified and evaluated."

These Recommendations are further elaborated in the Commentary to the Guidelines. In particular, as regards the role of corporate boards, the new Commentary provides as follows:

"102. Enterprises' commitments to co-operation, transparency and tax compliance should be reflected in risk management systems, structures and policies. In the case of enterprises having a corporate legal form, corporate boards are in a position to oversee tax risk in a number of ways. For example, corporate boards should proactively develop appropriate tax policy principles, as well as establish internal tax control systems so that the actions of management are consistent with the views of the board with regard to tax risk. The board should be informed about all potentially material tax risks and responsibility should be assigned for performing internal tax control functions and reporting to the board. A comprehensive risk management strategy that includes tax will allow the enterprise to not only act as a good corporate citizen but also to effectively manage tax risk, which can serve to avoid major financial, regulatory and reputation risk for an enterprise." 29

\section{Risk differentiation framework}

A further strategy is to use a risk differentiation framework to promote greater transparency about the tax agency's risk profile of the taxpayer. This could involve sharing with the company the tax agency's view of tax risk associated with the particular taxpayer group. This move towards a more cooperative, real time, risk management approach has been called a 'game-changer'.

Risk Differentiation Frameworks assign a risk category (based on an objective assessment of the likelihood and consequences of non-compliance) to a particular taxpayer within a market segment (for example, large companies). By informing

${ }^{29}$ OECD (2011), OECD Guidelines for Multinational Enterprises, OECD Publishing. http://dx.doi.org/10.1787/9789264115415-en. 
the taxpayer of how they are viewed by the tax agency, often facilitates dialogue that helps both parties to better manage their risk profile.

As tax agency resources are finite, they need to make choices about where to allocate their resources, while increasing transparency. The RDF allows them to make more informed choices, so that the focus is on taxpayers presenting the highest risk to the integrity of the tax system. Approaches such as Australia's Annual Compliance Arrangements invite companies to a mutual sharing of perceived tax risks. They offer a "no surprises" approach that minimises the risk of subsequent audit activity.

Strategies of this nature work well in complementing the risk management frameworks of large businesses. The sunlight of transparency provides a new paradigm that could change cultures:

"Companies told us that they have already started responding to the new era of risk and uncertainty; they are embedding tax risk management more prominently within their corporate governance approach, opening more lines of communication with their board and audit committee and tax policy-makers and tax administrators. $72 \%$ of companies say they are pursuing a more open and collaborative relationship with a tax administrator.,"30

\section{The focus on small business}

Small business is a key sector for many economies. However it is prone to significant risks, such as the challenges posed by the cash economy and because of the role played by businesses in the operation of VAT systems. As a result many tax agencies devote a high percentage of their resources to this sector.

Support for small business broadly falls under three key themes:

1. Firstly through tangible assistance, such as business assistance visits and an empathetic approach to businesses in short term financial difficulties (including payment arrangements for tax debts).

2. Secondly, tax agencies help businesses facing unfair competition by protecting them from businesses abusing the tax system. For example, compliance activities such as audits and firmer debt action (as appropriate) ensure that honest businesses are not disadvantaged by the non-compliant behaviour of others. Data matching and the publication of financial benchmarks are being used increasingly to counter evasion practices.

3. Thirdly, leading tax agencies are constantly seeking to make it easier and cheaper for businesses to comply, through better ways of reporting information. $^{31}$ Another way to make it easier for taxpayers is by improving the design of the tax agency's processes and products, utilizing user-based design. Compliance costs can be reduced by working with the

\footnotetext{
${ }^{30}$ EY 2011-12 Tax risk and controversy survey, 'A new era of global risk and uncertainty', 2012.

${ }^{31}$ For example, through the use of Standard Business Reporting (SBR).
} 
community in designing products and processes that are user friendly and rely on natural systems.

\section{Providing certainty and consistency}

Perhaps the two key features which single out tax administrations as being of a gold class standard are the degree of consistence and the level of certainty they provide in their operations. The best way to provide certainty and consistency is to apply the rule of law. ${ }^{32}$

A tax administration that operates in accordance with the law has legitimacy and is able to collect the tax that is properly payable. Such an administration provides the consistency in its activities that is conducive to a positive climate for investment. Importantly, in such an environment the rights of taxpayers are safeguarded by their ability to appeal to the courts.

There are two counterfactuals to a tax administration that operates in accordance with the law. One is of a tax agency that deals with taxpayers arbitrarily, capriciously or oppressively. Such an approach will overtime disengage the community from their ownership of the tax system and alienate or dissuade investment.

A different counterfactual sees the tax office operating in the domain of an elected government. Even with the best of intention tax agencies that supplement the law without legal authority are in effect making tax policy on the run. Their actions can result in the reshaping of the law to what the tax agency thinks it ought to be, rather than what the legislature intended.

A proper purposive interpretation of the law may be able to make the law work, and is to be encouraged. However, unsanctioned extra statutory concessions, which in effect are ultra vires, are likely overtime to create considerable uncertainty. ${ }^{33}$ Administrative practices that are not underpinned by the law can create an uneven playing field. Moreover they remove the taxpayer's redress to the courts if taxpayer-benign practices (which often tend to be abused) are subsequently removed by the tax agency.

\section{CONCLUSION}

The rate and pace of change is accelerating. On the policy front it is likely that the short to medium term will continue to be volatile and evolutionary. Tax policymakers foresee even more change ahead as they seek to protect the tax base and raise revenue from an evolving mix of taxes.

Leading tax administrations embrace change and channel it into innovative ways to add value. They are refining and fine tuning their understanding of taxpayer needs and risks. Building on this knowledge they are developing differentiated

\footnotetext{
${ }^{32}$ Australian Commissioner of Taxation, 'The Rule of Law: a corporate value', Law Council of Australia - Rule of Law conference, 2007.

${ }^{33}$ See Bellinz Pty Ltd v FCT, 98 ATC 4634
} 
responses. They are taking a holistic and integrated approach in addressing the causes of non-compliance, preferably through preventative strategies. In addition they are working with the community and key leverage groups, such as tax practitioners and software developers, to make the tax system easier, cheaper and more personalised for taxpayers. And they are cooperating globally to reduce international tax risks. Leading tax administrations are transparent and accountable, building trust and confidence in the community they serve. They foster a positive investment climate. In an era of global risk and uncertainty, they provide the consistency and certainty that is the pot of gold at the end of the rainbow. 


\section{REFERENCES}

Australian Tax Office for Commonwealth of Australia (2012). Tax Practitioner Action Plan. Australian Government.

Australian Taxation Office for the Commonwealth of Australia (2012). 'The effective use of analytics in public administration: The ATO Experience', Australian Government

Australian Commissioner of Taxation (2007), 'The Rule of Law: a corporate value', Law Council of Australia - Rule of Law conference.

Bakker, A., \& Kloosterhof, S. (2009) 'Tax Risk Management: From Risk to Opportunity'. Amsterdam, Netherlands: IBFD Leviner, S. (2009). 'A New Era of Tax Enforcement: From 'Big Stick' to Responsive Regulation', Michigan Law School, 42, 381-429.

Braithwaite, V. (2007). 'Responsive Regulation and Taxation', Law \& Policy, 29(1), 3-10.

Evans, C. (2014). The fiscal outlook for South Africa: challenges and opportunities', South African Institute of Tax Professionals, Tax Indaba 2014.

Ernst and Young (2007). Tax risk: External Change, Internal Change Global Tax Risk Survey 2006. Retrieved from

https://www2.eycom.ch/publications/items/global_tax_risk_survey_2006/ey_global_ta x_risk_survey_2006_e.pdf

Ernst and Young (2012). 2011-12 Tax risk and controversy survey, 'A new era of global risk and uncertainty'. Retrieved from http:/www.ey.com/GL/en/Services/Tax/2011-12Tax-risk-and-controversy-survey; and

James, S., Murphy, K., \& Reinhart, M. (2004). 'Taxpayer' Charter: A Case Study in Tax Administration'. Journal of Australian Taxation, 7(2), 336-356. Retrieved from http://69.195.124.80/ jausttax/?s=Taxpayer+charter+Case+Study+in+Tax+Administrat ion

KPMG (2009). Tax Department Survey, Good, Better, Best: The race to set global standards in tax management. KPMG's 2009 Tax Department Survey.

Lexis Nexis/Butterworths (2007). Tax Risk Management.

OECD (1990). Taxpayers' Rights and Obligations. Centre for Tax Policy and Administration Tax guidance series. Paris, France: OECD Publishing.

OECD (2006). Using Third Party Information Reports to Assist Taxpayers Meet their Return Filing Obligations - Country Experiences With the Use of Pre-populated Personal Tax Returns. Forum of Tax Administration Taxpayer Services Sub-group. Centre for Tax Policy and Administration

OECD (2008). Study into the Role of Tax Intermediaries. Paris, France: OECD Publishing. 
OECD (2009). Standard Business Reporting. Forum on Tax Administration Taxpayer Services Sub-Group. Retrieved from http://www.oecd.org/tax/administration/43384923.pdf

OECD (2011), 'OECD Guidelines for Multinational Enterprises'. Paris, France: OECD Publishing http://dx.doi.org/10.1787/9789264115415-en.

OECD (2012). Right from the Start: Influencing the Compliance Environment for Small and Medium Enterprises. Forum on Tax Administration: SME Compliance Sub-Group.

OECD (2012). Working Smarter in structuring the administration, in compliance, and through legislation and Working smarter in revenue administration Using demand management strategies to meet service delivery goals. Forum on Tax administration.

OECD (2013), Action Plan on Base Erosion and Profit Shifting, OECD Publishing. http://dx.doi.org/10.1787/9789264202719-en.

OECD (2013). Corporate Governance and Tax Risk Management. Forum on Tax Administration.

OECD (2013). Co-operative Compliance: A Framework. From Enhanced Relationship to Co-operative Compliance. Retrieved from http://www.oecd.org/ctp/administration/cooperative-compliance.htm

Parkinson, M. (2014). Fiscal sustainability \& living standards - the decade ahead. The Sydney Institute, Sydney: Australia. Retrieved from http://www.treasury.gov.au/PublicationsAndMedia/Speeches/2014/Fiscal_sustainability

Preston, J. (2012), 'Shaping the Tax System', PWC Tax administration: Global Trends, 2012. Retrieved from https://www.pwc.com/en_GX/gx/tax/publications/assets/pwc-globaltax-policy-trends.pdf

Warren, N. A. (2004). 'Tax: Facts, Fiction and Reform' Tax facts and tax reform \& Australian Tax Research Foundation, Sydney. “Australia's Future Tax System" Report to the Treasurer, (December 2009), Commonwealth of Australia, 2010. 